\title{
Efeito alelopático de extrato aquoso de folhas de Azadirachta indica A. Juss. em alface, soja, milho, feijão e picão-preto
}

\section{Allelopathic effect of aqueous extract of Azadirachta indica A. Juss. on lettuce, soybeans, maize, beans and Bidens pilosa}

\author{
Helena Cristina Rickli ${ }^{1 *}$; Andrea Maria Teixeira Fortes ${ }^{2}$; Paulo Sérgio Siberti da \\ Silva $^{3}$; Daiane Maria Pilatti ${ }^{4}$; Daniele Regina Hutt ${ }^{5}$
}

\section{Resumo}

\begin{abstract}
A família Meliaceae foi identificada como um dos grupos mais promissores para o controle biológico, pois a maioria das espécies possui compostos biologicamente ativos. Dentre as espécies, o Nim (Azadirachta indica A. Juss.) é a que mais se destaca pela sua alta eficiência e baixa toxidade, empregada no controle de insetos, fungos e nematóides. O objetivo deste trabalho foi verificar o potencial alelopático do extrato aquoso de folhas frescas de Nim sobre a germinação de alface, soja, milho, feijão e picãopreto, como forma de controle dessa invasora. O extrato foi obtido através da trituração de $200 \mathrm{~g} / \mathrm{L}$ de folhas frescas de Nim, considerado extrato $100 \%$, e diluído em água destilada nas concentrações de $80,60,40$ e $20 \%$, além da testemunha com apenas água. As sementes foram mantidas em câmara de germinação à temperatura de $25^{\circ} \mathrm{C}$, com fotoperíodo de $12 \mathrm{~h}$ de luz. $\mathrm{O}$ extrato aquoso prejudicou a porcentagem de germinação e comprimento médio de raiz de alface, que tiveram valores de $1 \%$ e $0,1 \mathrm{~cm}$ respectivamente. Para soja, o extrato afetou negativamente o tempo médio de germinação e velocidade media de germinação. Houve redução drástica do comprimento médio de raiz à medida que aumentou a concentração para soja, milho e feijão. Para Bidens pilosa todos os parâmetros analisados foram afetados negativamente, demonstrando sensibilidade ao extrato. O bioensaio realizado em laboratório demonstrou que o extrato aquoso de folhas frescas de Azadirachta indica possui efeito alelopático sobre todas as espécies estudadas.
\end{abstract}

Palavras-chave: Alelopatia. Nim. Plantas cultivadas. Invasora.

\begin{abstract}
The family Meliaceae has been identified as one of the most promising for biological control, as most species have biologically active compounds. Among the species, the Neem (Azadirachta indica A. Juss) is that stands out most for its efficiency and low toxicity, and it is utilized to control insects, fungi and nematodes. The aim of this work was to verify the allelopathic potential of aqueous extract of fresh leaves of Neem on germination of lettuce, soybeans, maize, beans and Bidens pilosa, as a way to control this weed. The extract was obtained by grinding $200 \mathrm{~g} / \mathrm{L}$ of fresh leaves of the Neem (considered extract $100 \%$ ) and diluting in distilled water at concentrations of $80,60,40$, and $20 \%$, and a control with only
\end{abstract}

\footnotetext{
1 Bióloga, pós-graduanda do curso de Mestrado em Agronomia, Universidade Federal do Paraná, UFPR, Rua dos Funcionários, 1540, Juvevê, CEP 80035-050, Curitiba, PR. Bolsista CAPES. E-mail: crisnenah@gmail.com

2 Bióloga, Dr ${ }^{\mathrm{a}}$, Prof ${ }^{\mathrm{a}}$ do Dept ${ }^{\mathrm{o}}$ de Ciências Biológicas, Universidade Estadual do Oeste do Paraná, UNIOESTE, Rua Universitária, 2069, Jardim Universitário, CEP 85819-110, Cascavel, PR. E-mail: andrea.fortes@unioeste.br

3 Biólogo, pós-graduando do curso de Mestrado em Agronomia, Universidade Estadual Paulista, UNESP. E-mail: sibertisilva@, hotmail.com

4 Bióloga, pós-graduanda do curso de Mestrado em Conservação e Manejo de Recursos Naturais, UNIOESTE. E-mail: dmpilatti@, hotmail.com

5 Bióloga, Universidade Estadual do Oeste do Paraná, UNIOESTE. E-mail: danielehutt@hotmail.com

*Autor para correspondência
} 
water. The seeds were kept in the germination chamber at a temperature of $25^{\circ} \mathrm{C}$, with photoperiod of 12 hours of light. The aqueous extract affected the germination percentage and average length root of lettuce, with values of $1 \%$ and $0.1, \mathrm{~cm}$ respectively. For the soybeans, the extract influenced negatively the average time of germination and average speed of germination. There was a drastic reduction of the average root length at higher concentration for soybean, corn and beans. For Bidens pilosa all the parameters analyzed were negatively affected, which means sensitivity to the extract. The bioassay performed in the laboratory showed that the aqueous extract of fresh leaves of Azadirachta indica has allelopathic effect on all species.

Key words: Allelopathy. Neem. Crops. Weeds.

\section{Introdução}

Dentre as espécies utilizadas na agricultura orgânica, a família Meliaceae foi identificada como um dos grupos mais promissores por possuir compostos biologicamente ativos que influenciam no desenvolvimento de outros organismos. Possui 51 gêneros e 550 espécies. Dentre as espécies mais estudadas da família encontra-se Trichilia pallida, Cinamomo ou Santa-bárbara (Melia azedarach L.) e Azadirachta indica conhecida como Nim ou Neem (GONÇALVES-GERVÁSIO, 2003).

A espécie Azadirachta indica A. Juss. é nativa da Índia (CARNEIRO, 2008), sendo empregada no controle de insetos, fungos e nematóides, indústria de cosméticos, fertilizantes, adubo, na produção de biomassa em propriedades rurais, reflorestamento e uso veterinário. É uma planta perene, de clima tropical, resistente à seca, de crescimento rápido, podendo alcançar 15 metros de altura, com copa densa (MARTINEZ, 2002). De suas folhas, frutos, sementes e tronco é possível produzir extratos biologicamente ativos com múltiplas propriedades (MOSSINI; KEMMELMEIER apud ARROTEIA; KEMMELMEIERI; MACHINSKI-JUNIOR, 2007).

Dentre os compostos ativos, o limonóide ou tetranortriterpenóide azadiractina é considerado o mais potente. Sua molécula é complexa e ainda não foi sintetizada, sendo necessária à extração do composto a partir da planta. É principalmente encontrada nas sementes, sendo que quantidades mais baixas são encontradas nas demais estruturas da planta. O composto é solúvel em água, biodegradável, não é bioacumulável e tem persistência bastante curta no ambiente, não apresentando risco de contaminação de água do subsolo (MARTINEZ, 2002).

Segundo alguns estudos realizados, os extratos de Nim podem causar fitotoxicidade em concentrações altas, mas depende da espécie de planta onde foi aplicado o extrato, sua idade e fase de desenvolvimento (MARTINEZ, 2002; MOSSINI; KEMMELMEIER, 2005). A fitotoxicidade manifesta-se como folhas enrijecidas, quebradiças, de cor verde-pálido, geralmente menores, com pontos necróticos. Segundo estudos de Sriavastava; Parmar apud Martinez (2002), soluções aquosas de óleo emulsionável acima de $1 \%$ podem causar fitotoxicidade e segundo Jakob apud Martinez (2002) o efeito fitotóxico do óleo ocorre somente na concentrações acima de $2 \%$, em plantas tratadas de milho, repolho, feijão e tomate, de duas e quatro semanas de idade.

Esses efeitos fitotóxicos podem, algumas vezes, serem descritos como sendo alelopáticos, sendo que, a alelopatia descreve a influência de um indivíduo sobre o outro, prejudicando ou favorecendo o segundo através de biomoléculas denominadas aleloquímicos (metabólitos secundários), produzidos pela planta e lançado no ambiente. A atividade dos aleloquímicos tem sido utilizada como alternativa ao uso de herbicidas, inseticidas e nematicidas (FERREIRA; AQUILA, 2000). As substâncias voláteis como terpenóides e etileno, podem ser liberadas facilmente das folhas ou outras partes da planta, podendo diretamente afetar o crescimento e desenvolvimento de plantas vizinhas. Esses compostos também podem ser lavados pela chuva e acumulados no solo (CARMO; FERREIRA, 2004). 
Assim, este trabalho teve como objetivo verificar o potencial alelopático de extrato aquoso de folhas frescas de Azadirachta indica A. Juss sobre a germinação de alface (Lactuca sativa L.) por ser uma espécie bioindicadora, soja (Glycine max (L) Merr.), milho (Zea mays L.), feijão (Phaseolus vulgaris L.) e picão-preto (Bidens pilosa L.), como forma de controle dessa invasora.

\section{Material e Métodos}

O bioensaio foi conduzido no Laboratório de Fisiologia Vegetal da UNIOESTE - Universidade Estadual do Oeste do Paraná - Campus Cascavel, no mês de janeiro de 2009. Os tratamentos foram constituídos por extrato aquoso de folhas frescas de Nim com 6 concentrações $(0,20,40,60,80$ e $100 \%)$. O tratamento $0 \%$ foi apenas com água destilada, considerado como testemunha.

As folhas de Nim foram utilizadas frescas, sendo coletadas no dia da montagem de cada experimento, na cidade de Foz do Iguaçu. Em seguida, 200 g dessas folhas foram lavadas em água corrente, trituradas com $1 \mathrm{~L}$ de água destilada com auxilio de um liquidificador, após filtração e verificação do $\mathrm{pH}$, constituindo o extrato aquoso bruto (100\%).

As sementes de soja da cultivar M- 595.5826 e de milho hibrido BMX 981 foram cedidas, respectivamente, nos meses de março e setembro de 2008 pela empresa COOPAVEL, situada na cidade de Cascavel - PR. As sementes de feijão chumbinho crioulas foram adquiridas de um pequeno produtor rural, situado na cidade de San Rafael - Paraguay, colhidas no mês de janeiro de 2009. As sementes foram mantidas refrigeradas até a realização dos experimentos.

Antes da montagem e avaliação de cada experimento, a bancada, a câmara de germinação, as mãos e os materiais foram desinfetados utilizandose um bactericida (Lysoform) e um fungicida (Nistatina), ambos na concentração de $10 \%$. Os rolos de papel Germiteste, constituídos por 3 camadas de papel e as placas de petri forradas por 3 folhas de papel filtro foram previamente esterilizados em autoclave a $121^{\circ} \mathrm{C}$ durante 20 minutos.

As placas de petri continham 25 diásporos de alface (Lactuca sativa L.) ou sementes de picãopreto (Bidens pilosa L.) por repetição, com $7 \mathrm{ml}$ de cada tratamento. Sendo que as sementes de picão-preto foram dispostas entre papel, por serem fotoblásticas negativas. As sementes de picãopreto permaneceram anteriormente em solução de Hipoclorito de Sódio $10 \%$ por 5 minutos para assepsia.

Os tratamentos contendo semente de soja (Glycine $\max$ (L) Merr.), milho (Zea mays L.) ou feijão (Phaseolus vulgaris L.), continham 50 sementes por repetição, para os testes de germinação, sendo dispostas entre papel germitest, ao qual anteriormente foi acrescentado água destilada e/ou extrato de volume de $2,5 \times$ o peso do papel, mantido em saco plástico. As sementes de feijão e soja permanecerem anteriormente em solução de Hipoclorito de Sódio $10 \%$ por 5 minutos para assepsia.

Todos os tratamentos consistiram de quatro repetições sendo armazenados em câmara de germinação, a aproximadamente $25^{\circ} \mathrm{C}$, com variação de mais ou menos $2^{\circ} \mathrm{C}$ e com fotoperíodo de 12 horas de luz. Foram efetuadas avaliações diárias, iniciando no dia seguinte a semeadura, sendo considerada como semente germinada aquela que apresentou no mínimo $2 \mathrm{~mm}$ de radícula (HADAS, 1986). Sendo verificado também o comprimento de raiz primária de 5 plântulas por repetição no último dia de avaliação. Os parâmetros analisados foram de porcentagem de germinação $(\% \mathrm{G})$, tempo médio de germinação (TMG), velocidade média de germinação (VMG) e comprimento médio da raiz primária (CMR).

O delineamento experimental foi inteiramente casualisado e os dados para porcentagem de germinação sofreram transformação arco seno da raiz quadrada da porcentagem. Além disso, 
foram realizadas análises quanto ao tempo médio de germinação efetuando-se cálculos segundo Edmond e Drapalha (1958). Já a velocidade média de germinação foi calculada segundo Labouriau (1983). Todos os parâmetros foram analisados através de análise de variância (Teste F) e as médias comparadas pelo teste de Tukey a $5 \%$ de probabilidade.

\section{Resultados e Discussão}

Com o presente ensaio, observou-se que o extrato aquoso de folhas de Nim interferiu na porcentagem de germinação de diásporos de alface. A diminuição significativa iniciou-se com a concentração de $40 \%$ do extrato, sendo que no tratamento de $80 \%$ a porcentagem de germinação foi de apenas $1 \%$ (Tabela 1). A velocidade média de germinação foi significativamente prejudicada pelo extrato na concentração de $80 \%$, diferindo da testemunha e do tratamento de $20 \%$. Apesar de diferir numericamente das concentrações 40, 60 e $100 \%$, não diferiu estatisticamente dos mesmos, o que confere semelhanças nos efeitos alelopáticos. Para o parâmetro comprimento médio de raiz, houve influência significativa em todas as concentrações do extrato, sendo maior a redução no comprimento na concentração de $80 \%$, chegando a apenas 0,10 $\mathrm{cm}$ de comprimento de raiz (Figura 1). Resultados semelhantes foram obtidos no trabalho de França et al. (2008), onde verificaram que extratos aquosos, metanólicos e hexanólicos de Nim (Azadirachta indica A. Juss.) exerceram efeitos negativos na porcentagem de germinação e índice de velocidade de germinação sobre plântulas de alface, sendo que o extrato aquoso foi o que teve menor porcentagem de germinação.

Tabela 1. Porcentagem de germinação $(\% \mathrm{G})$, tempo médio de germinação (TMG), velocidade media de germinação (VMG) e comprimento médio da raiz primaria (CMR) de diásporos de alface submetidos ao extrato aquoso de folhas frescas de Nim. Cascavel - PR/ 2009.

\begin{tabular}{lclll}
\hline Tratamento \% & G & TMG (dias) & VMG (sementes/dia) & CMR (cm) \\
\hline Testemunha & $66 \mathrm{a}$ & $2,02 \mathrm{ab}$ & $0,4988 \mathrm{a}$ & $1,10 \mathrm{a}$ \\
$20 \%$ & $48 \mathrm{a}$ & $2,01 \mathrm{ab}$ & $0,5109 \mathrm{a}$ & $0,36 \mathrm{bc}$ \\
$40 \%$ & $27 \mathrm{~b}$ & $2,37 \mathrm{a}$ & $0,4285 \mathrm{ab}$ & $0,36 \mathrm{bc}$ \\
$60 \%$ & $20 \mathrm{~b}$ & $1,72 \mathrm{a}$ & $0,4129 \mathrm{ab}$ & $0,40 \mathrm{~b}$ \\
$80 \%$ & $1 \mathrm{c}$ & $0,5 \mathrm{~b}$ & $0,1250 \mathrm{~b}$ & $0,10 \mathrm{c}$ \\
$100 \%$ & $3 \mathrm{c}$ & $1,12 \mathrm{ab}$ & $0,2250 \mathrm{ab}$ & $0,18 \mathrm{bc}$ \\
C. V. $\%$ & 20,21 & 41,47 & 43,57 & 29,98 \\
\hline
\end{tabular}

Médias seguidas de mesma letra na coluna não diferem entre si pelo teste de Tukey, a $5 \%$ de probabilidade. 


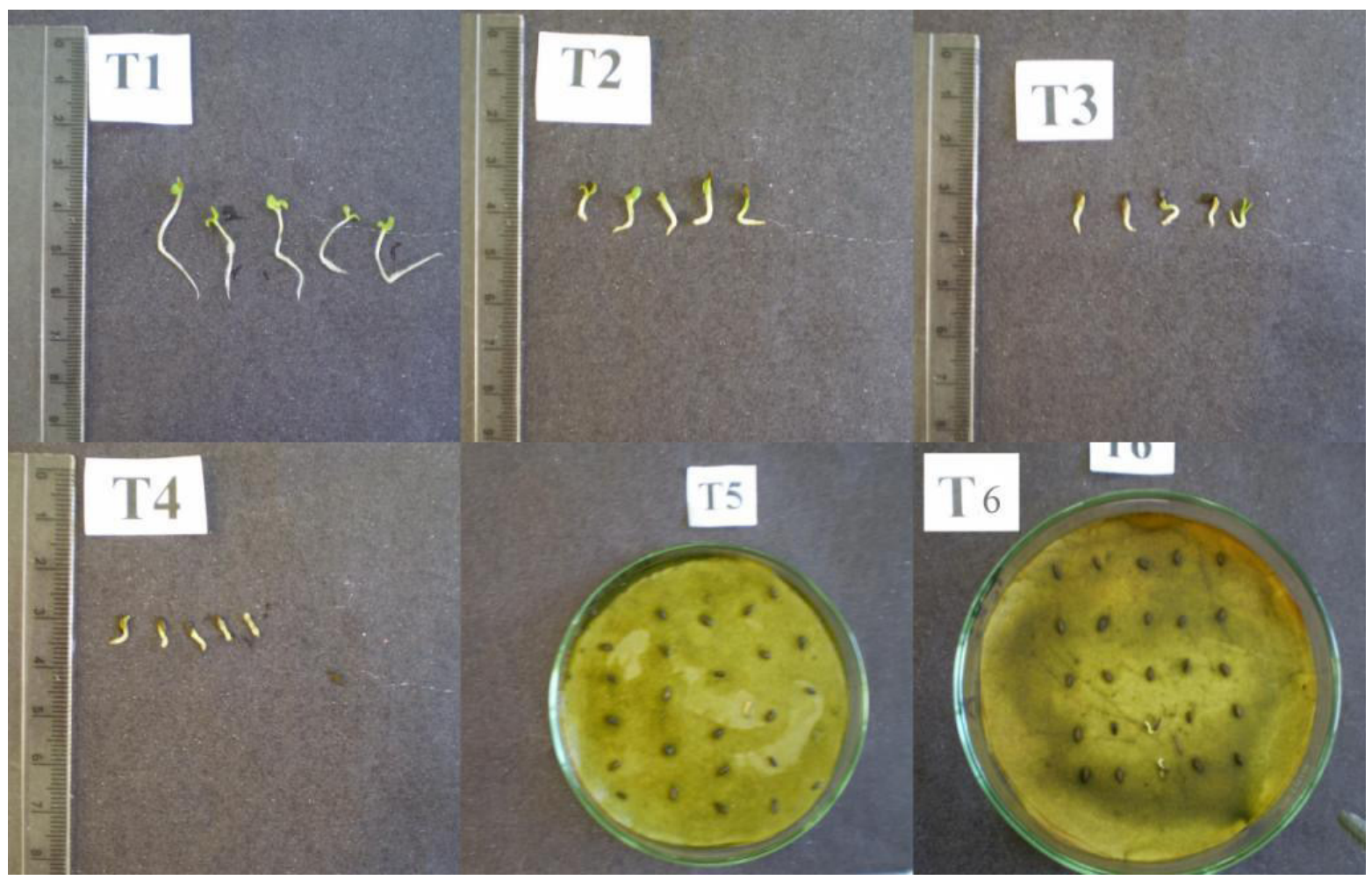

Figura 1. Plântulas de alface sob extrato aquoso de folhas de Nim. (T1) Testemunha. (T2) Extrato a 20\%. (T3) Extrato a 40\%. (T4) Extrato a 60\%. (T5) Extrato a 80\%. (T6) Extrato a 100\%. Fotos em escalas diferentes.

Essas alterações nas variáveis analisadas indicam um provável efeito alelopático do extrato de folhas frescas de Nim sobre sementes de alface, já que a mesma é considerada uma espécie bioindicadora por ser sensível a vários aleloquímicos (FERREIRA, 2004).

Já para as sementes de soja (Glycine max (L.) Merr.) a porcentagem de germinação não foi afetada por nenhuma concentração do extrato (Tabela 2). Porém, o tempo médio de germinação e velocidade média de germinação foram afetados significativamente a partir da concentração de $40 \%$, onde aumentou o tempo médio de germinação, de 1,03 dias na testemunha até 2,06 dias no tratamento
$100 \%$, e diminuiu a velocidade média de germinação, com 0,7850 para a testemunha e 0,4853 para a concentração de $100 \%$. Essas influências negativas sobre o tempo médio de germinação e velocidade média de germinação pode prejudicar a colheita do agricultor, por alterar a uniformidade na produção. Para a variável comprimento médio de raiz o extrato inibiu o crescimento da raiz em todas as concentrações, de maneira significativa. A redução do comprimento ocorreu de maneira drástica em relação à testemunha em todos os tratamentos (Figura 2), reduzindo de $14,27 \mathrm{~cm}$ a $2,80 \mathrm{~cm}$ na concentração de $20 \%$ até 1,05 na concentração de $100 \%$. 
Tabela 2. Porcentagem de germinação (\%G), tempo médio de germinação (TMG), velocidade media de germinação (VMG) e comprimento médio da raiz primaria (CMR) de sementes de soja submetidos ao extrato aquoso de folhas frescas de Nim. Cascavel - PR/ 2009.

\begin{tabular}{lllll}
\hline Tratamento \% & \multicolumn{1}{c}{ G } & TMG (dias) & VMG (sementes/dia) & CMR (cm) \\
\hline Testemunha & $97,45 \mathrm{a}$ & $1,30 \mathrm{c}$ & $0,7850 \mathrm{a}$ & $14,27 \mathrm{a}$ \\
$20 \%$ & $97 \mathrm{a}$ & $1,53 \mathrm{bc}$ & $0,6616 \mathrm{ab}$ & $2,80 \mathrm{~b}$ \\
$40 \%$ & $95,5 \mathrm{a}$ & $1,85 \mathrm{a}$ & $0,5418 \mathrm{bc}$ & $2,4 \mathrm{~b}$ \\
$60 \%$ & $97 \mathrm{a}$ & $1,80 \mathrm{ab}$ & $0,5553 \mathrm{bc}$ & $1,56 \mathrm{~b}$ \\
$80 \%$ & $94,5 \mathrm{a}$ & $1,98 \mathrm{a}$ & $0,5079 \mathrm{c}$ & $1,22 \mathrm{~b}$ \\
$100 \%$ & $98,5 \mathrm{a}$ & $2,06 \mathrm{a}$ & $0,4853 \mathrm{c}$ & $1,05 \mathrm{~b}$ \\
C. V. $\%$ & 9,20 & 7,74 & 10,33 & 21,68 \\
\hline
\end{tabular}

Médias seguidas da mesma letra na coluna não diferem entre si pelo teste de Tukey, a 5\% de probabilidade.

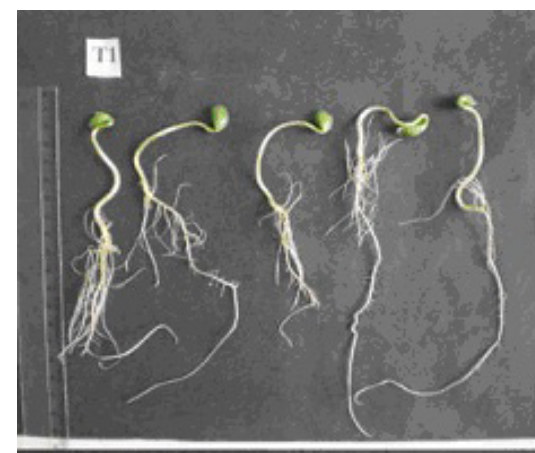

T4

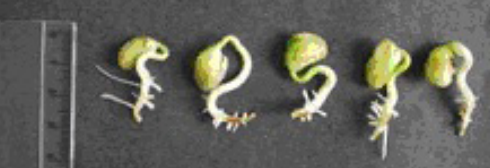

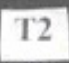
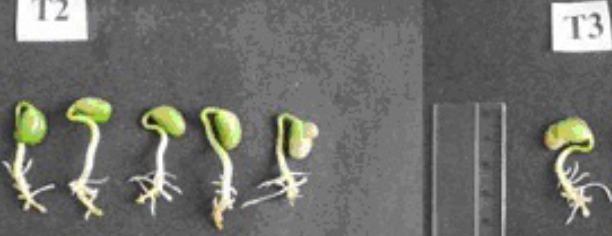

T5

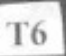

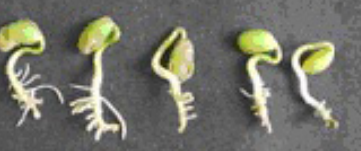

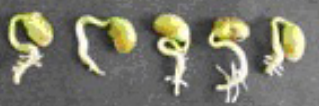

Figura 2. Plântulas de soja sob extrato aquoso de folhas de Nim. (T1) Testemunha. (T2) Extrato a 20\%. (T3) Extrato a 40\%. (T4) Extrato a 60\%. (T5) Extrato a 80\%. (T6) Extrato a 100\%. 
O mesmo ocorreu no trabalho realizado por Machado (2008) que estudando a germinação de soja sobre influência de extrato aquoso de folhas de Cinamomo (Melia azedarach L.), espécie pertencente à mesma família que o Nim, a Meliaceae, verificou alterações no comprimento médio de raiz, velocidade média de germinação e tempo médio de germinação com a aplicação do extrato.

Ao analisar os dados para sementes de milho (Zea mays L.), o extrato aquoso de Nim não afetou a porcentagem de germinação, tempo médio de germinação e velocidade média de germinação (Tabela 3). Porém, pode-se observar que para o comprimento médio de raiz o extrato exerceu efeito inibitório, sendo significativas as alterações a partir da concentração de $20 \%$, com valores inferiores à testemunha, com diminuição drástica de $16,52 \mathrm{~cm}$ na testemunha para $4,71 \mathrm{~cm}$ no tratamento de $20 \%$, chegando 2,22 cm no extrato puro (Figura 3). Esses resultados diferem dos apresentados por Machado (2008) que para o extrato aquoso de Cinamomo não verificou influência inibitória no comprimento médio de raiz, sendo que na concentração de $20 \%$ de extrato houve um estímulo no comprimento, indicando que a aplicação de extratos vegetais podem tanto inibir quanto estimular o crescimento de plântulas, devido a presença de aleloquímicos (FARIA et al., 2009).

Tabela 3. A porcentagem de germinação (\%G), tempo médio de germinação (TMG), velocidade media de germinação (VMG) e comprimento médio da raiz primaria (CMR) de sementes de milho submetidos ao extrato aquoso de folhas frescas de Nim. Cascavel - PR/ 2009.

\begin{tabular}{lllcr}
\hline Tratamento & \%G & TMG (dias) & VMG (sementes/dia) & CMR (cm) \\
\hline Testemunha & $100 \mathrm{a}$ & $2 \mathrm{a}$ & $0,4987 \mathrm{a}$ & $16,52 \mathrm{a}$ \\
$20 \%$ & $100 \mathrm{a}$ & $2,02 \mathrm{a}$ & $0,4940 \mathrm{a}$ & $4,71 \mathrm{~b}$ \\
$40 \%$ & $100 \mathrm{a}$ & $2,04 \mathrm{a}$ & $0,4903 \mathrm{a}$ & $3,02 \mathrm{bc}$ \\
$60 \%$ & $98 \mathrm{a}$ & $2,02 \mathrm{a}$ & $0,4963 \mathrm{a}$ & $2,50 \mathrm{bc}$ \\
$80 \%$ & $99,5 \mathrm{a}$ & $2,02 \mathrm{a}$ & $0,4950 \mathrm{a}$ & $2,15 \mathrm{c}$ \\
$100 \%$ & $98,55 \mathrm{a}$ & $2,02 \mathrm{a}$ & $0,4938 \mathrm{a}$ & $2,22 \mathrm{c}$ \\
C. V. $\%$ & 3,99 & 1,26 & 1,24 & 21,25 \\
\hline
\end{tabular}

Médias seguidas da mesma letra na coluna não diferem entre si pelo teste de Tukey, a 5\% de probabilidade. 


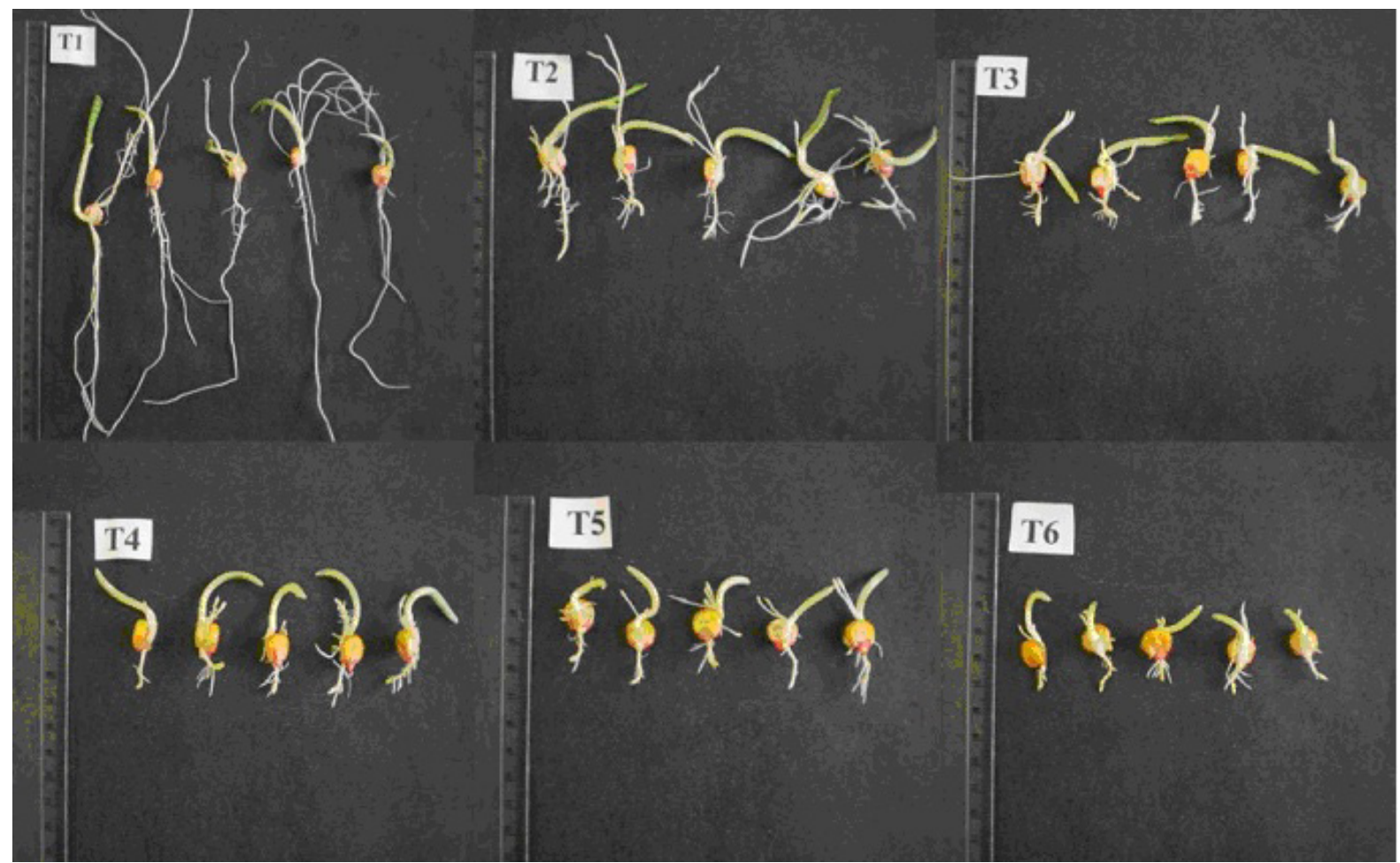

Figura 3. Plântulas de milho sob extrato aquoso de folhas de Nim. (T1) Testemunha. (T2) Extrato a 20\%. (T3) Extrato a $40 \%$. (T4) Extrato a 60\%. (T5) Extrato a 80\%. (T6) Extrato a 100\%.

Assim como o milho, as sementes de feijão do extrato, passando de 11,93 cm na testemunha não sofreram influência do extrato aquoso de Nim para 3,22 cm no tratamento de 20\% (Figura 4). sobre a porcentagem de germinação, velocidade $\mathrm{O}$ mesmo aconteceu com Silva, Crotti e Cunha média de germinação e tempo médio de germinação (2007) que notou em seu experimento, que o extrato (Tabela 4). Já o comprimento médio de raiz foi hidroalcoólico de Nim sobre sementes de feijão (P. significativamente alterado a partir da concentração vulgaris) reduziu significativamente a média de de 20\%, diminuindo com o aumento da concentração comprimento radicular.

Tabela 4. Porcentagem de germinação (\%G), tempo médio de germinação (TMG), velocidade media de germinação (VMG) e comprimento médio da raiz primaria (CMR) de sementes de feijão submetidas ao extrato aquoso de folhas frescas de Nim. Cascavel - PR/ 2009.

\begin{tabular}{llllc}
\hline Tratamento $\%$ & G & TMG (dias) & VMG (sementes/dia) & CMR (cm) \\
\hline Testemunha & $100 \mathrm{a}$ & $1,24 \mathrm{a}$ & $0,8093 \mathrm{a}$ & $11,93 \mathrm{a}$ \\
$20 \%$ & $98 \mathrm{a}$ & $1,43 \mathrm{a}$ & $0,7061 \mathrm{a}$ & $3,22 \mathrm{~b}$ \\
$40 \%$ & $97,5 \mathrm{a}$ & $1,28 \mathrm{a}$ & $0,7873 \mathrm{a}$ & $1,82 \mathrm{c}$ \\
$60 \%$ & $99 \mathrm{a}$ & $1,31 \mathrm{a}$ & $0,7704 \mathrm{a}$ & $1,31 \mathrm{c}$ \\
$80 \%$ & $97,5 \mathrm{a}$ & $1,45 \mathrm{a}$ & $0,6911 \mathrm{a}$ & $1,16 \mathrm{c}$ \\
$100 \%$ & $97,5 \mathrm{a}$ & $1,43 \mathrm{a}$ & $0,7072 \mathrm{a}$ & $1,44 \mathrm{c}$ \\
C. V. $\%$ & 1,88 & 10,42 & 10,30 & 11,50 \\
\hline
\end{tabular}

Médias seguidas da mesma letra na coluna não diferem entre si pelo teste de Tukey, a 5\% de probabilidade. 


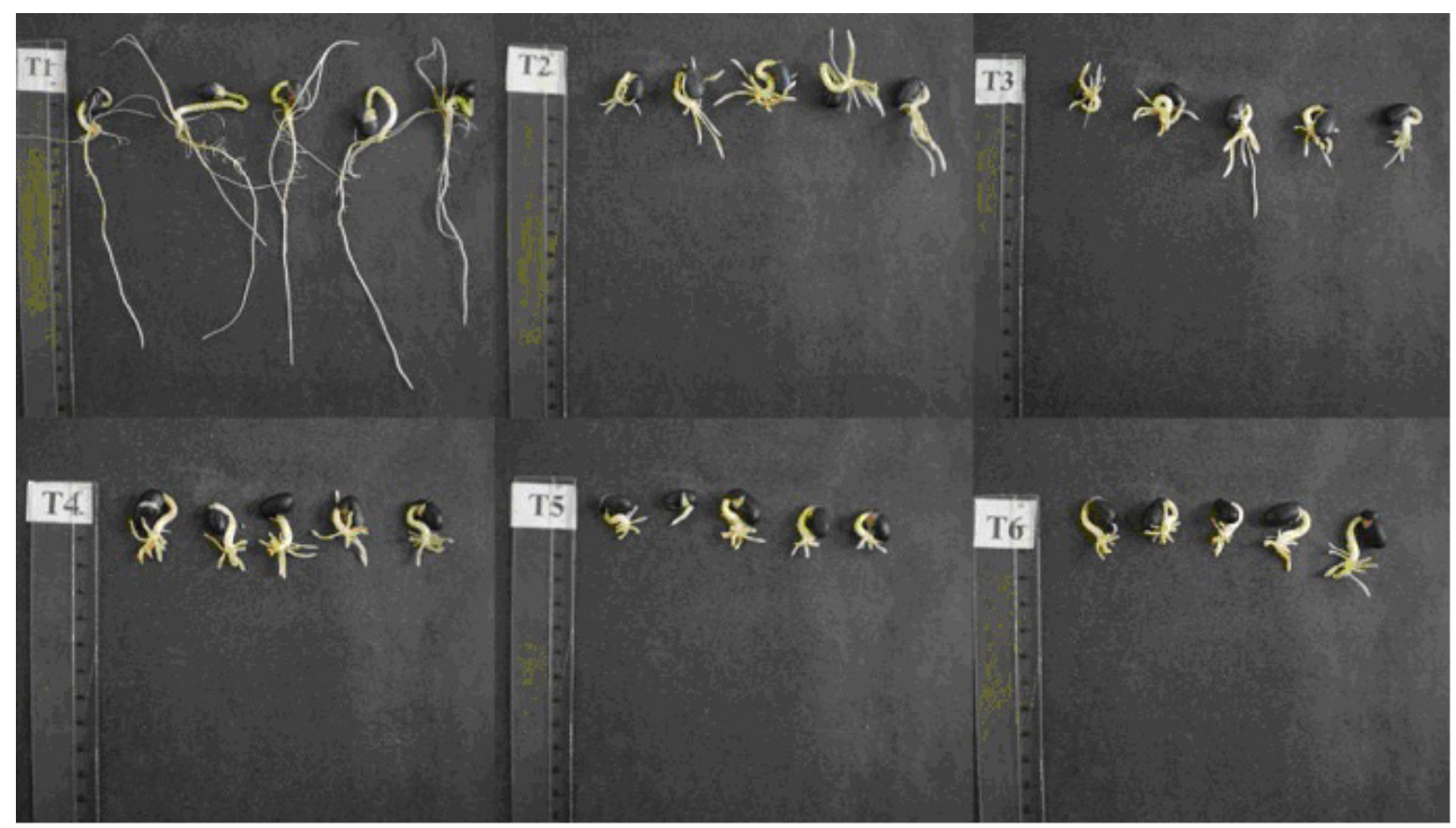

Figura 4. Plântulas de feijão sob extrato aquoso de folhas de Nim. (T1) Testemunha. (T2) Extrato a 20\%. (T3) Extrato a 40\%. (T4) Extrato a 60\%. (T5) Extrato a 80\%. (T6) Extrato a 100\%.

As alterações encontradas para comprimento médio de raiz para as culturas de soja, milho e feijão podem ser explicadas por Ferreira (2004) que afirmam que a germinação é menos sensível aos aleloquímicos do que o crescimento da plântula, sendo que o efeito alelopático se dá sobre a velocidade de germinação ou sobre outro parâmetro do processo como comprimento médio de raiz, como observado no presente trabalho.

No experimento com sementes de picão-preto (Bidens pilosa L.) foi possível notar que essa espécie é sensível ao extrato aquoso de Nim. Verificouse que a porcentagem de germinação diminuiu de acordo com o aumento da concentração do extrato, sendo significativo nas concentração de $80 \%$ e
100\% (Tabela 5), com 7\% e 12\% de germinação respectivamente. O tempo médio de germinação foi afetado significativamente apenas no extrato puro com aumento do tempo de germinação, onde a testemunha foi de 3,74 e na concentração $100 \%$ passou para 9,78. Entretanto, para a velocidade média de germinação houve diferença significativa prejudicial em todas as concentrações. A partir da concentração de $40 \%$ do extrato, pode-se perceber que houve diferença significativa no comprimento médio da raiz (Figura 5), reduzindo o tamanho de acordo com o aumento da concentração, com 4,2 e 0,44 para a testemunha e extrato puro, respectivamente. O que demonstra um potencial alelopático negativo sobre essa espécie. 
Tabela 5. Porcentagem de germinação (\%G), tempo médio de germinação (TMG), velocidade media de germinação (VMG) e comprimento médio da raiz primaria (CMR) de sementes de picão-preto submetidos ao extrato aquoso de folhas frescas de Nim. Cascavel - PR/ 2009.

\begin{tabular}{lllcc}
\hline Tratamento \% & G & TMG (dias) & VMG (sementes/dia) & CMR (cm) \\
\hline Testemunha & $79 \mathrm{a}$ & $3,74 \mathrm{~b}$ & $0,2679 \mathrm{a}$ & $4,20 \mathrm{a}$ \\
$20 \%$ & $81 \mathrm{a}$ & $5,48 \mathrm{ab}$ & $0,1855 \mathrm{~b}$ & $3,06 \mathrm{a}$ \\
$40 \%$ & $76 \mathrm{a}$ & $6,74 \mathrm{ab}$ & $0,1584 \mathrm{bc}$ & $1,74 \mathrm{~b}$ \\
$60 \%$ & $53 \mathrm{ab}$ & $7,80 \mathrm{ab}$ & $0,1328 \mathrm{bc}$ & $0,68 \mathrm{~b}$ \\
$80 \%$ & $7 \mathrm{c}$ & $7 \mathrm{ab}$ & $0,0812 \mathrm{c}$ & $0,47 \mathrm{~b}$ \\
$100 \%$ & $12 \mathrm{bc}$ & $9,78 \mathrm{a}$ & $0,1024 \mathrm{c}$ & $0,44 \mathrm{~b}$ \\
C. V. $\%$ & 31,96 & 3,76 & 23,05 & 33,10 \\
\hline
\end{tabular}

Médias seguidas da mesma letra na coluna não diferem entre si pelo teste de Tukey, a $5 \%$ de probabilidade.

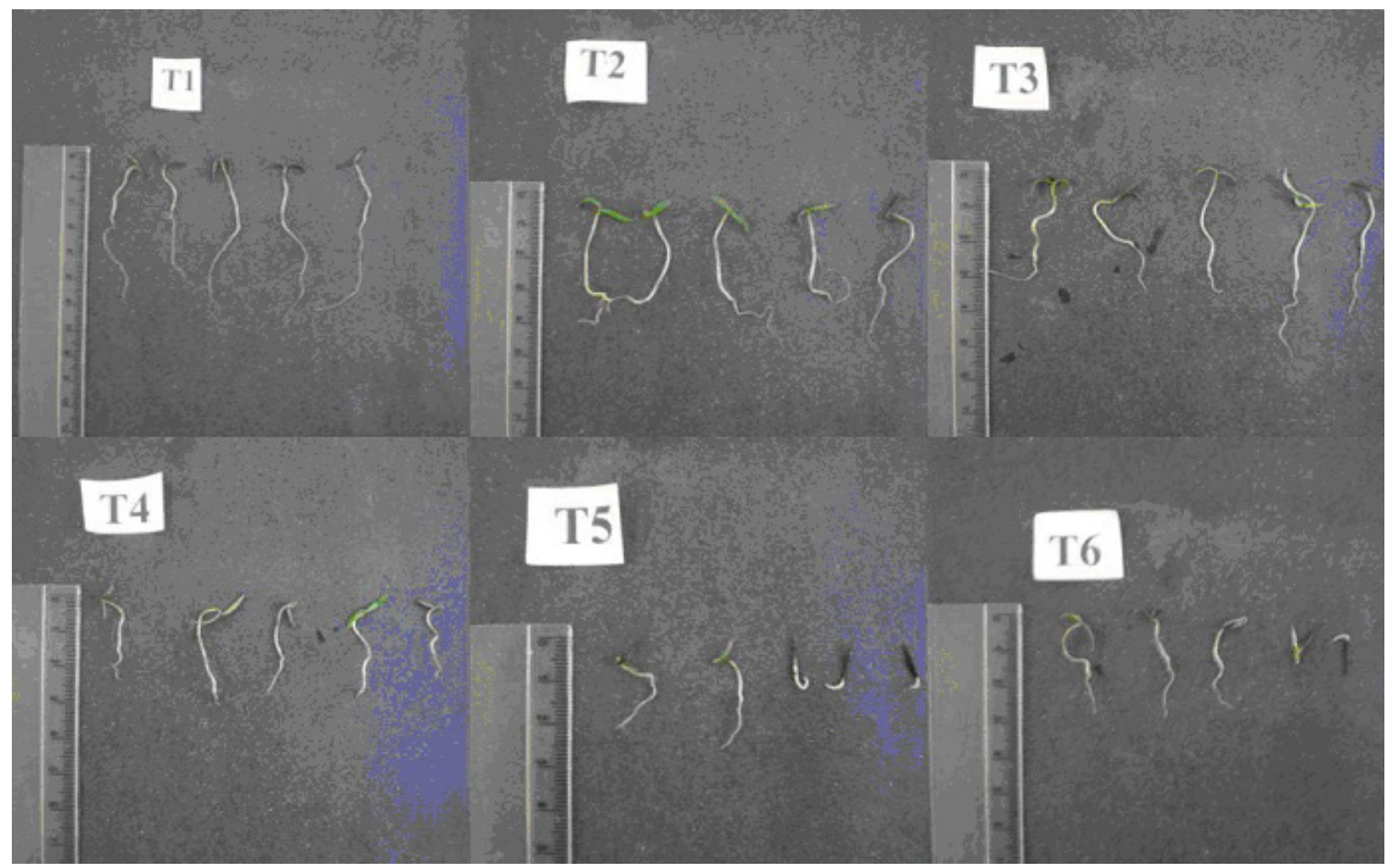

Figura 5. Plântulas de picão-preto sob extrato aquoso de folhas de Nim. (T1) Testemunha. (T2) Extrato a 20\%. (T3) Extrato a 40\%. (T4) Extrato a 60\%. (T5) Extrato a 80\%. (T6) Extrato a 100\%. Fotos em escalas diferentes.

Outros estudos mostram influencia de extratos vegetais sobre a germinação e crescimento de picão-preto que colaboram com o presente trabalho. Como o estudo realizado por França et al. (2008) verificaram em seus estudos que diferentes extratos de folhas de Nim exerceram efeitos negativos na porcentagem de germinação e índice de velocidade de germinação de sementes de picão-preto. O mesmo ocorreu com Machado (2008) onde verificou interferência de extrato aquoso de Cinamomo em todos os parâmetros estudados de picão-preto, sendo que, para a porcentagem de germinação no extrato 
de Cinamomo a 40\% reduziu à 6\% de germinação.

\section{Conclusões}

O extrato aquoso de folhas frescas de Nim exerce efeito alelopático negativo sobre a germinação de sementes de alface, soja e picão-preto. Também influencia o desenvolvimento de raiz dessas espécies, ocorrendo o mesmo para as plântulas de feijão e milho.

\section{Referências}

ARROTEIA, C. C.; KEMMELMEIERI, C.; MACHINSKI-JUNIOR, M. Efeito dos extratos aquoso e oleoso de Nim [Azadirachta indica A. Juss (Meliaceae)] na produção de patulina em maçãs contaminadas por Penicillium expansum. Ciência Rural, Santa Maria, v. 37, n. 6, p. 1518-1523, 2007.

CARMO, F. M. S.; FERREIRA, K. M. Princípios básicos em alelopatia.In: CONGRESSO NACIONAL DE BOTÂNICA, 55., Viçosa, 2004. Anais... Viçosa: Universidade Federal de Viçosa, 2004. p. 2-10.

CARNEIRO, S. M. T. P. G. Efeito do Nim (Azadirachta indica) sobre o oídio e antracnose. Informe de Pesquisa, Londrina, n. 155, ago. 2008. Disponível em: <http:// www.iapar.br/arquivos/File/zip_pdf/IP155.pdf>. Acesso em :21 out. 2008.

EDMOND, J. B.; DRAPALHA, W. J. The effects of temperature, sand, soil, and acetone on germination of okra seeds. Proceedings of the American Society for Horticultural Science, Itahaca, v. 71, p. 428-434, 1958.

FARIA, T. M.; GOMES JUNIOR, F. G.; SÁ, M. E. de; CASSIOLATO, A. M. R. Efeitos alelopáticos de extratos vegetais na germinação, colonização micorrízica e crescimento inicial de milho, soja e feijão. Revista Brasileira de Ciência do Solo, Viçosa, v. 33, n. 6, p. 1625-1633, 2009.

FERREIRA, A. G.; AQUILA, M. E. A. Alelopatia: uma área emergente da ecofisiologia. Revista Brasileira Fisiologia Vegetal, Campinas, v. 12, p. 175-204, 2000. Edição Especial.

FERREIRA, A. G. Interferência: competição e alelopatia, In: FERREIRA, A. G.; BORGHETTI, F. (Org.). Germinação: do básico ao aplicado. Porto Alegre: Artmed, 2004. cap. 16, p. 251-262.

FRANÇA, A. C.; SOUZA, I. F. SANTOS, C. C.; OLIVEIRA, E. Q.; MARTINOTTO, C. Atividades alelopáticas de Nim sobre o crescimento de sorgo, alface e picão-preto. Ciência Agrotecnologia, Lavras, v. 32, n. 5, p. 1374-1379, 2008.

GONÇALVES-GERVÁSIO, R. C. R. Efeito dos extratos de Tichilla pallida Swartz e Azadirachta indica A. Juss (Meliaceae) sobre Tuta absoluta (Meyrick) e seu parasitóide Trichogamma pretiosum Riley. 2003. Tese (Doutorado em Ciências, Área de Concentração: Entomologia) - Escola Superior de Agricultura Luiz de Queiroz, Piraciacaba.

LABOURIAU, L. G. A germinação de sementes. Secretaria Geral da OEA: Washington, 1983. 173p.

MACHADO, A. Indicação da alelopatia de Cinamomo (melia azedarach l.) na agricultura orgânica. Cascavel: UNIOESTE, 2008. 47 p. (Trabalho monográfico).

MARTINEZ, S. S. O Nim: Azadirachta indica- natureza, usos múltiplos, produção. Londrina: IAPAR, 2002. 142 p.

MOSSINI, S. A. G.; KEMMELMEIER, C. A árvore Nim (Azadirachta indica A. Juss): múltiplos usos. Acta Farmacéutica Bonaerense, Buenos Aires, v. 24, n. 1, p. 139-148, 2005.

SILVA, J. P.; CROTTI, A. E. M.; CUNHA, W. R. Antifeedant and allelopathic activities of the hydroalcoholic extract obtained from Neem (Azadirachta indica) leaves. Revista Brasileira de Farmacognosia, Curitiba, v. 17, n. 4, p. 529-532, 2007. 
